\title{
The effect of rubber versus concrete passageways in cubicle housing on claw health and reproduction of pluriparous dairy cows
}

\author{
Laura A. Boyle, John F. Mee*, Paul J. Kiernan \\ Teagasc, Moorepark Dairy Production Research Centre, Fermoy, Co. Cork, Ireland \\ Accepted 31 July 2006 \\ Available online 20 September 2006
}

\begin{abstract}
The effect of covering the passageways and feed face of a cubicle house with rubber flooring was compared to concrete in terms of claw health, behaviour and reproductive performance of dairy cows from a grass-based milk production system. Sixty-two, autumn calving, pluriparous Holstein-Friesian cows were introduced to the housing treatments prior to calving. Foot lesions were scored at housing, 1, 7, 12 and 16 weeks post-partum. The behaviour (activity, posture, and location) of all cows was recorded by instantaneous scan sampling over $24 \mathrm{~h}$ once per week from ca. 3 weeks pre-partum to 12 weeks post-partum. Estrous activity was recorded by visual observation three times daily using tail-paint and continuously by radiotelemetry from 1 week after calving until the end of the breeding season.

The rubber flooring had a negligible beneficial effect on heel erosion but no effect on haemorrhage or dermatitis scores and no effect on the proportion of cows affected by severe lesions. Furthermore, there were no benefits for estrous expression or subsequent reproductive performance. There were no differences between treatments in time spent standing by cows, but cows on concrete stood more in the cubicles, while cows on the rubber flooring stood more at the feed face. This suggests that cows prefer to stand on comfortable surfaces while not feeding and that they can use well-bedded, comfortable cubicles for standing to get relief for their feet from concrete floors. This also explains the lack of a difference between treatments in claw health.

(C) 2006 Elsevier B.V. All rights reserved.
\end{abstract}

Keywords: Dairy cows; Flooring; Claw health; Behaviour; Reproduction; Estrous

* Corresponding author. Tel.: +35325 42387.

E-mail address: john.mee@teagasc.ie (J.F. Mee).

0168-1591/\$ - see front matter (C) 2006 Elsevier B.V. All rights reserved.

doi:10.1016/j.applanim.2006.07.011 


\section{Introduction}

Housing of dairy cows during the winter months is a common component of Irish grass-based milk production systems. This facilitates feeding when grass supply is limited and the ground is wet. Cubicle houses with fully slatted concrete or solid concrete floors are common. However, such systems can have adverse effects on dairy cow welfare (Fregonesi and Leaver, 2001) and reproductive performance (Lucy, 2001).

Lameness is one of the most important welfare issues for dairy cows and it has significant economic implications. Lameness is a multifactorial condition. However, prolonged standing on concrete is an important predisposing factor (Bergsten and Frank, 1996). Furthermore, falling on slippery concrete floors is responsible for most upper leg lameness (Philipot et al., 1994). Cows' feet are especially sensitive to damage at parturition and in early lactation (Webster, 2002). Minimising external stresses on the feet at this time, i.e. by housing on straw, reduced the severity of sole haemorrhages in heifers (Webster, 2001). Vermunt and Greenough (1994) recommend that cows being kept on hard surfaces for long periods of time should be given access to areas covered with a softer surface to relieve their feet and help reduce the prevalence and incidence of lameness. Indeed, there is ample evidence from the literature that simply providing cows with mats or bedding in the cubicles goes some way towards reducing cases of foot lesions (e.g. Leonard et al., 1994). Anecdotal evidence suggests that the use of cushioned flooring in the feed alleys of new cubicle houses, or retro-fitting it in existing barns is becoming common. However, research data to support its benefits are lacking and often contradictory. For example, Jungbluth et al. (2003) found that sole haemorrhages in dairy cows were less severe on rubber floors compared to concrete. In contrast, Vokey et al. (2001) found no differences in the severity of sole lesions or incidence of clinical lameness between cattle housed with access to rubber or concrete alleyways over a 16-week period.

As cattle are able to distinguish between walking surfaces that differ in traction it is likely that the flooring surface can modify their behaviour. Indeed, the gait of dairy cows is affected by floor surface, with softer and more slip resistant flooring reducing various measures of gait abnormality (Jungbluth et al., 2003; Telezhenko and Bergsten, 2005). Softness is one of the most important properties of a floor for dairy cows (Irps, 1983) and they prefer to walk and stand on soft flooring instead of on concrete (Telezhenko et al., 2004). Tucker et al. (2006) reported that cows preferred to use sawdust covered flooring compared to concrete. This preference was apparent in the amount of time spent eating, amount of feed consumed and time spent standing on the sawdust but not eating. Nevertheless, neither Tucker et al. (2006) nor Fregonesi et al. (2004) found an effect on time spent eating of providing rubber flooring in front of the feed face. Hence the effect of flooring on feed intake is variable. In both of the former studies, cows spent longer standing at or near the feed face without eating when it was covered with rubber flooring.

Estrus detection plays a major role in the reproductive success of dairy cattle. However, a comparison of estrous events in Irish dairy cows over the last two decades shows a reduction in the intensity of estrus (Mee, 2004). This problem is compounded by housing cows on concrete which reduces estrous expression when compared to dirt surfaces (De Silva et al., 1981; Britt et al., 1986; Vailes and Britt, 1990; Rodtian et al., 1996). The reasons suggested for this reduction in estrous expression include hesitancy by cows to mount on a concrete surface, particularly where they have foot problems and temporary inhibition of mounting activity after cows fall due to slippery flooring. Recently it was shown that cows' claws slip twice as far on slurry-covered concrete compared to dry concrete (Van Der Tol et al., 2005). These authors considered cows mounting each other during estrus as a risky behaviour with high potential risk of slipping. Where milk is produced from grass, the majority of cows calve in the spring, but in a proportion of herds 
cows are calved in the autumn to supply the winter milk market. As housing coincides with the breeding season low estrous expression can lead to poor reproductive performance in these animals (Ryan, 1998). Lucy (2001) concluded that the most likely cause of a decrease in estrous expression is "the increased utilisation of dairy confinement housing with concrete floors". The effects of claw lesions and lameness, and the stress associated with close confinement and slippery under-foot conditions may also combine to affect estrous expression. Recently, Blowey (2005) stated that 'cows walking on rubber adopt a longer and more natural stride, bruising of the corium is reduced, and the animals are more likely to express 'natural' activity such as estrous behaviour and grooming'.

The aim of this study was to evaluate the effect of providing dairy cows with cushioned flooring in the passageways between rows of cubicles and at the feed face on claw health, behaviour and reproductive performance. The hypothesis was that the provision of cushioned flooring would offer protection to the cows' feet, particularly in late pregnancy and early lactation, which would in turn improve claw health. Furthermore, it was hypothesised that cows on the cushioned flooring would have an enhanced expression of estrus owing to more comfortable underfoot conditions that would in turn lead to improvements in reproductive performance.

\section{Materials and methods}

\subsection{Animals, housing and management}

Sixty-six autumn-calving, pluriparous Holstein-Friesian cows were blocked firstly on expected calving date then on previous lactation milk yield and parity in August 2003. Cows from each block $(n=33)$ were assigned randomly using a table of random numbers to two treatments (CONCRETE or MAT) prior to calving until at least 16 weeks post-partum (PP) when they were turned out to grass. Cows were housed approximately 4 weeks prior to their expected calving date. The first cows were housed on September 1st, 2003. Six cows calved within 1 week of housing ( 2 in CONCRETE, 4 in MAT). On average, cows were housed 2.9 weeks prior to calving up to a maximum of 5 weeks. All cows were at pasture since March 2003 and the majority were housed in the same accommodation as that used for the current study during the winter of 2002/2003. The rubber flooring was not in place at that time. All the cows were housed on concrete during previous winters. As four cows were dropped from the study for health or management reasons, an evaluation of the results of blocking was carried out to assess whether the resultant treatment groups (CONCRETE, $n=32$, MAT, $n=30$ ) were similar with regard to possible confounding variables. The mean (S.D.) values for parity, milk yield (litres) and lactation stage (days in milk) at onset of treatments for the CONCRETE and MAT groups were 3.2 (1.37) and 3.2 (1.50), 7871 (1652.0) and 7786 (1339.3) and 333 (89.4) and 356 (94.2), respectively. Animals were accommodated in halves of a cubicle house equidistant from the adjoining milking parlour at Moorepark Dairy Production Research Centre. The house had an automatic scraper which cleaned the passageways approximately once per hour. The passageway at the feed face was $4.8 \mathrm{~m}$ wide and between the cubicles $3.0 \mathrm{~m}$ wide giving $6.6 \mathrm{~m}^{2}$ of passageway floor space per cow, at a slope of $1.5 \%$. The ratio of cows to cubicles (mattress-bedded, $2.2 \mathrm{~m} \times 1.2 \mathrm{~m}$, Pasture Mat ${ }^{\mathbb{R}}$, O'Donovan Engineering, Coachford, Co. Cork) was 1:1. The cubicles were of a cantilever design (O'Connell et al., 1991). The house was divided in two with the passageways on one side and in front of the feed face covered with rubber flooring (R.J. Mooney Anti-Lameness Mat ${ }^{\mathbb{R}}$, Unit 4c, Avonbeg Industrial Estate, Longmile Road, Dublin 12, Ireland) [i.e. MAT]. The rubber flooring was $15 \mathrm{~mm}$ thick (10 $\mathrm{mm}$ solid and $5 \mathrm{~mm}$ studs) with a hammer non-slip surface pattern. On the other side the concrete was not covered. Cows were removed from their respective treatments to a straw-bedded calving pen approximately $24-48 \mathrm{~h}$ before calving until the first milking (colostrum) when they were returned to the cubicle house on the day of or the day after calving. Cows were offered grass silage alone before calving and grass silage plus $8 \mathrm{~kg}$ of concentrate per cow after calving. The diets were fed using computerised feed 
boxes (1.2 m wide, Griffith Elder Ltd., Bury St. Edmunds, Suffolk, UK) with 18 boxes in each half of the house and each box accessible by up to three cows.

Ten days prior to the start of the breeding season (mating start date; 4 December, 2003) all cows calved more than 35 days were examined by transrectal ultrasonography and those with reproductive problems (ovarian cysts, moderate/severe endometritis) were treated. Following the mating start date, cows were artificially inseminated (AI) at spontaneous estrus, between 35 and 113 days after calving. One commercial technician performed all AI. Natural service was not used. A single ejaculate from one sire of known normal fertility (semen analysis: 60:40 alive:dead sperm; motility: good) was used to serve all cows. Cows were examined at 30 and 60 days after AI for pregnancy by ultrasonography. The breeding season lasted approximately 12 weeks from 4 December, 2003 to 24 February, 2004 (82 days).

\subsection{Recordings}

The hind feet of all cows were evaluated and correctively trimmed according to Dutch foot trimming principles in July, 2003. Thereafter each animal was examined at housing, 1, 7, 12 and 16 weeks post-partum by the same person. All four hind claws were cleaned and lightly trimmed in a restraining chute. A sliver of horn was pared from the whole area of the weight-bearing surface to expose fresh horn. Haemorrhages were localised as to six zones of the sole and white line. The severity of haemorrhages observed in each zone was scored on a six-point scale as per Greenough and Vermunt (1991). The scores for the six zones of all four claws were added to give a total haemorrhage score for each animal at each inspection. There is a lack of consensus in the literature as to whether interdigital and digital dermatitis (ID and DD, respectively) are separate problems (e.g. Vokey et al., 2001) or manifestations of the same pathology (e.g. Manske et al., 2002). Hence, all lesions determined by gross examination of the plantar area of the interdigital skin and the bulb area of the hind feet were collectively referred to as dermatitis and rated on a four-point (0-3) scale as per Peterse (1980). The sum of the scores for each hind foot yielded a dermatitis score for each cow. Evaluation of the severity of heel horn erosion was according to a four-point (0-3) scoring system also described by Peterse (1980). The scores for the four hind claws were summed to give a heel erosion score for each cow.

The behaviour of all cows in each treatment was monitored by instantaneous scan sampling over $24 \mathrm{~h}$ once per week on Wednesday from September 3rd until March 3rd, 2004. The activity (ruminate, feed, sleep, idle, active [self or allo-groom, scratch, drink, etc.]), posture (ventral/lateral lying, standing) and location (cubicle, half in cubicle, passageway, feeding stall, feed face) of all animals in each of the housing treatments was recorded onto a checklist every 15 min during the following 6 time periods: 08:30-11:00, 12:00-15:00, 16:30-19:00, 20:00-23:00, 24:00-02:30 and 04:30-07:00 h. The layout of the house precluded the use of video recorders. Hence, all behaviour data were collected by direct observation. Three trained observers were responsible for data collection during two of these periods each, with each observer recording data on the two treatments simultaneously. Each week the observers switched observation periods. During observations it was necessary for the observer to move quietly between the cows in order to identify individuals by their freeze brand markings or ear identity tags.

Estrous events were recorded by both visual observations using tail-paint and by radiotelemetry. Emulsion paint was applied to the tail head of all animals approximately 1 week after calving. Visual observations were carried out at least three times daily for $30 \mathrm{~min}$ from 1 week after calving. The tail head area of each cow was shaved 2 weeks before expected calving date. HeatWatch ${ }^{\mathbb{R}}$ (DDx Incorporated, Denver, CO) radiotelemetric transmitters were glued in place at the time of first tail-paint application 1 week after calving. Standing estrus was defined by HeatWatch as $\geq 3$ mounts of a duration of more than $1 \mathrm{~s}$ in $4 \mathrm{~h}$. The duration of standing estrus was defined as the length of time from the first recorded standing event to the time of the last recorded standing event consistent with the definition of standing estrus. A HeatWatch standing estrus of low intensity and low duration was defined as one of $<7 \mathrm{~h}$ and $<10$ mounts. The size of the sexually active group was defined by the number of cows in HeatWatch standing estrus simultaneously. Milk sampling was carried out to detect false estrous events ( $\geq 3$ HeatWatch mounts within $4 \mathrm{~h}$ with high, $\geq 3 \mathrm{ng} / \mathrm{ml}$, milk progesterone $\left(\mathrm{MP}_{4}\right)$ concentration). A milk sample was collected on the day of (am or pm), or the day after (am) any cow had $\geq 3$ HeatWatch mounts. Samples were preserved with a potassium dichromate tablet (Lactab Mark III, Thompson \& Capper 
Ltd., Cheshire, UK), stored at $4{ }^{\circ} \mathrm{C}$ and analysed in batches by enzymeimmunoassay for progesterone concentration (Ridgeway Science Ltd., Rodmore Mill Farm, Alvington, Gloucestershire, UK). Intra- and inter-assay coefficients of variation were 6.1 and $6.5 \%$, respectively. The minimum detection limit, calculated using absorption of the blank standard minus two standard deviations, was $0.5 \mathrm{ng} / \mathrm{ml}$. True standing estrus was recorded where a HeatWatch standing estrus was recorded with an $\mathrm{MP}_{4}$ value $<3 \mathrm{ng} / \mathrm{ml}$ and unless otherwise stated, all HeatWatch results refer to true standing estrus.

\subsection{Statistical analysis}

All analyses were performed using the Statistical Analysis System software package (SAS, 2000). The foot lesion (haemorrhage score, dermatitis score and heel erosion score), behaviour (time spent standing, lying, feeding, sleeping, idling, ruminating and active and time spent in different locations while standing) and radiotelemetry (duration of true standing estrus, number of mounts during true standing estrus) data were analysed by repeated measures analysis of variance (ANOVA) using general linear mixed models (MIXEDprocedure) with treatment as a fixed effect and cow as the random effect. The foot lesion and behaviour data were non-normally distributed (UNIVARIATE procedure) and transformations did not correct for this. Thus, all foot lesion and behaviour data were ranked for analyses (RANK procedure). Behaviour data were averaged across weeks for pregnancy and lactation and the mean of both periods were used in the analyses. Pre-housing haemorrhage, dermatitis and heel erosion scores were included as covariates in the analyses of the foot lesion data. The radiotelemetry data were also non-normally distributed (UNIVARIATE procedure). They were subjected to $\log 10$ (number of mounts received) or square root transformation (duration of standing estrus) to normalise distributions. Choice of transformation was based on the normality characteristics (mean, median, mode, extreme observations, skewness, kurtosis, Sharpiro-Wilk statistic, box and normal distribution plots) of the resultant distributions. Back-transformed means and $95 \%$ confidence intervals $(\mathrm{CI})$ are presented. The main effect of treatment was forced into all models with other explanatory variables, including interactions (treatment by time), being selected based on a stepwise forward-backward algorithm with an entry and stay significance level of $P<0.05$ based on the $F$-test. The level of autocorrelation in the analyses was evaluated by including the autoregression correlation coefficient (AR) for unequally spaced time data as the covariate structure in the MIXED procedure. The model assumption of homogeneity of variance was tested using Levene's test for homogeneity confirming homoscedasticity among treatments groups. Model-fit was determined by choosing models with the minimum finite-sample corrected Akaike Information Criteria (AICC). Continuous reproduction variables (calving to first standing estrus interval, calving to first service interval and calving to conception interval) were subjected to analysis of variance, with repeated measures where within-cow comparisons were made, using the GLM procedure in SAS. The models included terms for treatment, time, interactions (treatment $\times$ time) and block. When the interaction terms were not statistically significant, the analysis was rerun without them. Categorical reproduction variables (number of true standing estrus events, number of standing estrus events of low intensity and low duration, number of cows in a sexually active group, number of false estrus events, number of cows submitted for service within 21 days of the mating start date, number of cows which conceived to first service, number of cows pregnant within 6 weeks of the mating start date and overall pregnancy rate) were analysed using the frequency procedure (FREQ procedure). Haemorrhage scores were collapsed into a severe category whereby any cow with at least one lesion scored 3 or higher was considered to have severe lesions (Bergsten et al., 1998). Furthermore, the numbers of cows in each treatment with at least one heel erosion or dermatitis lesion scored greater than 1 was recorded. The number of animals in each treatment with severe lesions was then analysed by Fishers exact test using the frequency procedure.

\section{Results}

There was no effect of floor surface on haemorrhage or dermatitis scores (Table 1). Both scores were significantly affected by time $(P<0.001)$. Haemorrhage scores 16 weeks 
Table 1

Least squares means \pm S.E.M. for haemorrhage, dermatitis and heel erosion scores of Holstein-Friesian cows in 2 treatments at 4 inspections

\begin{tabular}{llllllll}
\hline Inspection & \multicolumn{2}{l}{ Concrete } & & & \multicolumn{2}{l}{ Mat } \\
\cline { 2 - 3 } & Haemorrhage & Dermatitis & Heel erosion & & Haemorrhage & Dermatitis & Heel erosion \\
\hline 1 week pp & $5.2 \pm 0.55$ & $0.8 \pm 0.21$ & $3.9 \pm 0.31$ & & $4.0 \pm 0.56$ & $1.2 \pm 0.22$ & $3.8 \pm 0.31$ \\
7 weeks pp & $4.2 \pm 0.55$ & $1.5 \pm 0.21$ & $5.7 \pm 0.31^{\mathrm{a}}$ & & $3.6 \pm 0.56$ & $1.8 \pm 0.22$ & $4.6 \pm 0.31^{\mathrm{a}}$ \\
12 weeks pp & $4.0 \pm 0.55$ & $1.7 \pm 0.21$ & $5.8 \pm 0.31$ & & $3.0 \pm 0.57$ & $1.7 \pm 0.22$ & $5.6 \pm 0.32$ \\
16 weeks pp & $5.6 \pm 0.55$ & $2.1 \pm 0.21$ & $5.9 \pm 0.31$ & & $6.5 \pm 0.57$ & $2.1 \pm 0.22$ & $6.2 \pm 0.32$ \\
\hline
\end{tabular}

* $\mathrm{pp}=$ Post-partum

a $P<0.05$.

Table 2

Proportion of cows (\% affected [number affected/number inspected]) in two treatments affected by heel erosion and dermatitis scores greater than 1 and haemorrhage scores of 3 or greater at five inspections

\begin{tabular}{llllllll}
\hline Inspection & \multicolumn{2}{l}{ Concrete } & & & Mat & \\
\cline { 2 - 3 } & Haemorrhage & Dermatitis & Heel erosion & & Haemorrhage & Dermatitis & Heel erosion \\
\hline Pre-housing & $3.2(1 / 31)$ & $0(0 / 31)^{\mathrm{a}}$ & $12.9(4 / 31)$ & & $6.7(2 / 30)$ & $20.0(6 / 30)^{\mathrm{a}}$ & $10.0(3 / 30)$ \\
1 week pp & $3.2(1 / 31)$ & $6.5(2 / 31)$ & $29.0(9 / 31)$ & & $0(0 / 30)$ & $20.0(6 / 30)$ & $30.0(9 / 30)$ \\
7 weeks pp & $6.5(2 / 31)$ & $29.0(9 / 31)$ & $64.5(20 / 31)$ & & $0(0 / 30)$ & $20.0(6 / 30)$ & $46.7(14 / 30)$ \\
12 weeks pp & $3.2(1 / 31)$ & $9.7(3 / 31)$ & $71.0(22 / 31)$ & & $0(0 / 30)$ & $23.3(7 / 30)$ & $73.3(22 / 30)$ \\
16 weeks pp & $16.1(5 / 31)$ & $6.5(2 / 31)$ & $77.4(24 / 31)$ & & $10.0(3 / 30)$ & $16.7(5 / 30)$ & $90.0(27 / 30)$ \\
\hline
\end{tabular}

${ }^{*} \mathrm{pp}=$ Post-partum

a $P<0.05$.

post-partum were significantly higher than at 1,7 and 12 weeks post-partum. Dermatitis scores at 7, 12 and 16 weeks post-partum were significantly higher than at 1 week post-partum. There was a time by treatment interaction for heel erosion scores $(P<0.05)$. CONCRETE cows had higher heel erosion scores 7 weeks post-partum compared to MAT cows $(P<0.05)$. Haemorrhage, heel erosion and dermatitis type lesions were all present prior to housing (89, 46 and $20 \%$ of cows affected, respectively). There was a higher proportion of MAT cows with a severe dermatitis type lesion prior to housing $(P<0.05)$ (Table 2$)$. There was no effect of treatment on the proportion of cows affected by such lesions at subsequent inspections $(P>0.05)$. There was no effect of treatment on the proportion of cows affected by severe haemorrhages or heel erosion at any inspection $(P>0.05)$ (Table 2$)$.

Table 3

Least squares means \pm S.E.M. for proportions of time cows spent engaged in different behaviours during the housing period

\begin{tabular}{llr}
\hline & Concrete & Mat \\
\hline Stand & $0.61 \pm 0.014$ & $0.60 \pm 0.016$ \\
Lie & $0.39 \pm 0.014$ & $0.40 \pm 0.016$ \\
Feed & $0.16 \pm 0.007$ & $0.15 \pm 0.008$ \\
Sleep & $0.03 \pm 0.002$ & $0.02 \pm 0.002$ \\
Idle & $0.31 \pm 0.009$ & $0.33 \pm 0.010$ \\
Ruminate & $0.40 \pm 0.007$ & $0.37 \pm 0.008$ \\
Active & $0.11 \pm 0.005$ & $0.12 \pm 0.005$ \\
\hline
\end{tabular}




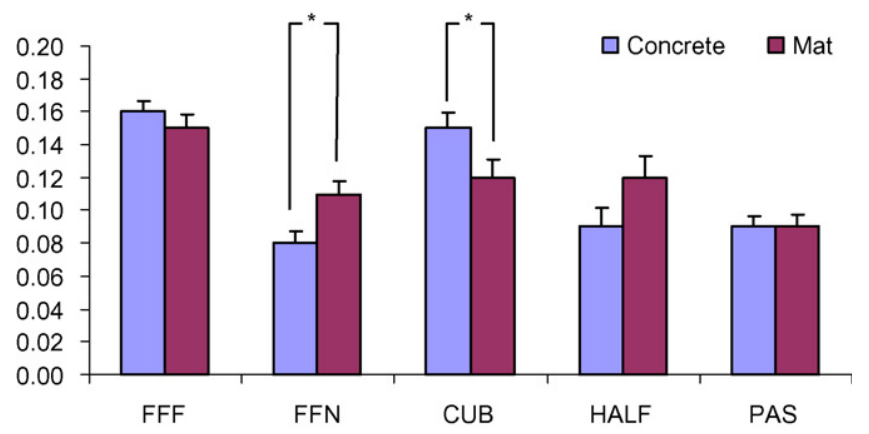

Fig. 1. Least squares means \pm S.E.M. for proportion of cows standing in different locations (FFF, feeding at face feed; FFN, close to feed face but not feeding; CUB, cubicle; HALF, partially in cubicle; PAS, passageway between rows of cubicles; $\left.{ }^{*} P<0.05\right)$

There were no effects of treatment on time spent standing or lying or time spent engaged in different behaviours (Table 3). MAT cows were observed standing close to the feed face, but not feeding, during a higher proportion of observations while there was a higher proportion of observations of CONCRETE cows standing in the cubicles $(P<0.05)$ (Fig. 1). All variables were significantly affected by time $(P<0.05)$.

Floor surface had no effect on standing estrous events (number of cows in estrus, interval between calving and first estrus, number of estrous events per cow) detected by visual observation and tail-paint between calving and the mating start date (data not shown) $(P>0.05)$. Floor surface also had no effect on standing estrus events detected by radiotelemetry prior to and during the breeding season $(P>0.05)$ (Table 4$)$. There were no significant interactions between treatment, estrus number (1-4) and the number of cows in estrus simultaneously (sexually active group; $1-6)$, hence only treatment effects are shown. The mean $(95 \% \mathrm{CI})$ duration of standing estrus (minimum-maximum 28-1297 min) increased with each succeeding estrus (standing

Table 4

Numbers, means and percentages for cows exhibiting standing estrous events detected by HeatWatch radiotelemetry from 62 Holstein-Friesian cows in 2 treatments

\begin{tabular}{|c|c|c|c|}
\hline Variable & Concrete & Mat & $P$ \\
\hline $\begin{array}{l}\text { Number of cows with HeatWatch standing } \\
\text { estrus events detected }\end{array}$ & 24 & 22 & NS \\
\hline $\begin{array}{l}\text { Interval between calving and first } \\
\text { standing estrus (days) }\end{array}$ & $49.0(3.98)$ & $57.1(4.10)$ & NS \\
\hline $\begin{array}{l}\text { Number of HeatWatch standing estrus events } \\
\text { with milk progesterone }<3 \mathrm{ng} / \mathrm{ml} \\
\text { (true standing estrus) }\end{array}$ & 37 & 36 & NS \\
\hline Mean $(\mathrm{CI})$ duration of true standing estrus (min.) & $437.3(302.95,596.11)$ & $424.3(286.84,588.60)$ & NS \\
\hline $\begin{array}{l}\text { Mean }(\mathrm{CI}) \text { number of mounts received } \\
\text { during true standing estrus }\end{array}$ & $7.0(5.14,9.42)$ & $8.0(5.78,10.96)$ & NS \\
\hline $\begin{array}{l}\text { Percentage of HeatWatch standing estrus events } \\
\text { which were of low intensity and low duration }\end{array}$ & $67(25 / 37)$ & $53(19 / 36)$ & NS \\
\hline Mean \pm S.E.M. number of cows in the sexually active group & $2.3(0.34)$ & $2.0(0.32)$ & NS \\
\hline $\begin{array}{l}\text { Percentage of HeatWatch standing estrus events with } \\
\text { milk progesterone } \geq 3 \mathrm{ng} / \mathrm{ml} \text { (false standing estrus) }\end{array}$ & $2.6(1 / 38)$ & $7.7(3 / 39)$ & NS \\
\hline
\end{tabular}


Table 5

Numbers, least squares means \pm S.E.M. and percentages for cows submitted for service during the breeding season from 62 Holstein-Friesian cows in 2 treatments

\begin{tabular}{llll}
\hline Variable & Concrete & Mat & $P$ \\
\hline $\begin{array}{l}\text { Number of cows } \\
\text { Percentage of cows submitted for service within }\end{array}$ & 32 & 30 & $60(18 / 30)$ \\
$\quad 21$ days of the start of the breeding season & & & NS \\
Interval between calving and first service (days) & $71.0(3.04)$ & $71.5(3.14)$ & NS \\
$\begin{array}{l}\text { Interval between calving and conception (days) } \\
\text { Percentage of cows conceived to first service }\end{array}$ & $79.6(5.81)$ & $48(14 / 29)$ & NS \\
$\begin{array}{l}\text { Percentage of cows pregnant within 6 weeks } \\
\text { of the start of the breeding season }\end{array}$ & $56(15 / 29)$ & $47(14 / 30)$ & NS \\
$\begin{array}{l}\text { Percentage of cows pregnant at the end } \\
\text { of the breeding season }\end{array}$ & $66(19 / 29)$ & $68(19 / 28)$ & NS \\
\hline
\end{tabular}

estrus 1: 292.6(203.69-397.48), standing estrus 2: 394.8 (269.49-543.88), standing estrus 3: 489.0 (249.73-807.80), standing estrus 4: 572.8 (260.63-1006.24), but was unaffected by the size of the sexually active group. The duration of first estrus was shorter than that of standing estrus 2 $(P<0.104)$ and standing estrus $3(P<0.089)$. The number of mounts received during a standing estrus (minimum-maximum 3-24) was unaffected by estrus number or the size of the sexually active group. False standing estrus was uncommon (5.2\%, 4/77 standing estrus). Floor surface had no significant effect on reproductive performance during the breeding season (Table 5).

\section{Discussion}

There are a limited number of studies of claw lesion development in housed spring calving cows from pasture based milk production systems (e.g. Leonard et al., 1994; Offer et al., 2004). However, there are very few studies of claw lesion development in autumn calving cows from such systems where housing and calving are often simultaneous. Furthermore, the studies that exist utilised heifers (Leonard et al., 1996; Leach et al., 1997). This makes comparison with the findings of this study difficult. In the current study, the scores of all three types of claw lesion were highest 16 weeks post-partum. Claw health was not monitored after this time as the cows were turned out to grass. Hence, it is possible that scores had not peaked and that there may have been an effect of flooring had the cows been housed for longer. Nevertheless, our findings are consistent with Leach et al. (1997) who reported that haemorrhage scores in autumn calving heifers peak within 2-4 months of calving.

Jungbluth et al. (2003) reported some advantages of rubber covered slats for haemorrhages in loose housed dairy cows. However, our results are in accordance with Vokey et al. (2001) who found no significant effects of rubber flooring on sole/white line haemorrhages. Vokey et al. (2001) suggest that differences between treatments in days in milk and parity may have masked a potential benefit of rubber flooring in their study. In our study, claw health was generally good. Very few cows were affected by severe haemorrhages probably owing to the relatively benign housing conditions. The concrete flooring was in very good condition, there was no exposure to stones or sharp objects, the cows had to walk a short distance to be milked and the cubicles were spacious and comfortable. This may have reduced the possibility of detecting differences between treatments. In addition, the fact that pluriparous cows were used meant that a high proportion of them were already affected by haemorrhagic lesions prior to the experiment. This 
may have further diminished our chances of detecting differences between the treatments. Primiparous cows are commonly used in studies evaluating the effect of housing practices on sole/white line lesion development (e.g. Livesey et al., 1998; Webster, 2001).

In accordance with Livesey et al. (1998) heel erosion scores increased in both treatments during the first 7 weeks post-partum. However, the deterioration was faster in the concrete treatment. Although the difference between treatments is not of major biological relevance (4.6 versus 5.7 considering a maximum possible score of 12) it suggests that the rubber flooring offered some protection to the heels. The effect was only found at the 7 weeks post-partum inspection which coincided approximately with peak lactation. This is when cows are at greatest risk of heel erosion (Bergsten and Herlin, 1996). These authors attributed the increased risk at this time to the increased volume of manure produced at peak lactation. Indeed, exposure to moisture and manure are risk factors for heel erosion (Philipot et al., 1994). However, there was no difference between the concrete and rubber flooring in terms of dirtiness as the automatic scraper was effective in keeping both floors clean. Considering the link between dirty, unhygienic housing conditions and forms of dermatitis (Bergsten, 2001) this also explains the lack of a difference between treatments in dermatitis scores. As the heel is the major weight-bearing surface of the claw it seems likely that mechanical forces must also play a part in heel erosion. Hence, the likelihood that the rubber was less abrasive than concrete might account for the difference observed. While heel erosion itself is rarely a direct cause of lameness, it can contribute to the problem (Bergsten and Pettersson, 1992) and as such has negative consequences for dairy cow welfare. Although the high number of animals in both treatments affected by moderate to severe heel erosion lesions 16 weeks post-partum causes some concern, it is likely that these lesions would have improved soon after turnout to pasture (Offer et al., 2000).

In accordance with both Fregonesi et al. (2004) and Tucker et al. (2006) cows on concrete spent more time standing in the mattress-bedded cubicles while cows on the cushioned flooring stood more in the alley close to the feed face. This suggests that cows have a preference for a comfortable place to stand when not eating. In agreement with Tucker et al. (2006) it seems likely that the degree to which cows stand in the cubicles is a reflection of the absence of comfortable places to stand outside of the cubicles. The fact that cows in both treatments had comfortable places to stand while not eating could also explain the lack of treatment differences in claw health. The cubicles used in this study were spacious and well bedded which would have made them attractive to the cows for standing in. Inadequacies in cubicle number, design, dimensions or in the bedding used might have made the cows less likely to use them (see Leonard et al., 1994, 1996). This would have conferred an advantage in terms of claw health to the rubber flooring. Nevertheless, rubber flooring should not be used to compensate for uncomfortable cubicles. Indeed Tucker et al. (2006) found that this increases alley lying which is undesirable. The results highlight the importance of considering the entire facility and not focusing on a single component when trying to improve the comfort of housed cows.

Anecdotal evidence suggests that cows on rubber flooring, being more comfortable standing, spend more time feeding. However, our results, in agreement with other studies (Stefanowska et al., 2001; Fregonesi et al., 2004) do not support this. The competitive feeding arrangement used in the current study may have made cows on rubber flooring reluctant to spend any more time than necessary feeding in spite of the comfortable underfoot conditions. Tucker et al. (2006) found that a softer surface in front of the feed face resulted in higher eating times in individually housed cows.

Flooring surface had no significant effect on standing estrous events detected by visual observation and tail-paint prior to the start of the breeding season. It might be speculated that if 
the rubber flooring had reduced sole haemorrhages, this might have increased cow comfort during estrous activity, whether mounting or being mounted, and hence, resulted in better estrous expression. The fact that the rubber flooring was probably as slippery as the concrete may also account for the lack of a treatment difference in estrous events. The grip afforded by floor surface is likely to have a critical effect on cow-to-cow interactions during standing estrus, with surfaces with a high grip coefficient resulting in more intense and prolonged estrous behaviour (Larkin et al., 2003; Britt et al., 1986; De Silva et al., 1981).

Flooring surface also had no significant effect on standing estrous events detected by radiotelemetry prior to and during the breeding season. These data provided a more complete picture of estrous behaviour on the two flooring surfaces throughout the entire day compared to visual observations. The lack of a difference between treatments is not surprising given the results from the visual observations and tail-paint. Larkin et al. (2003) showed that duration of estrus and number of mounts detected by telemetry were similar on rubber-covered slats, pasture and straw but significantly increased compared to concrete slats. Though this comparison showed that estrous activity in beef animals was greater on rubber-covered slats compared to concrete slats, the construction of the raised grooved rubber slat covers provided some resistance to slippage in addition to cushioning. The former attribute of the rubber covered slat, absent in the rubber flooring used in the current study, in addition to differences in rubber consistency, may have been contributory factors to differences in estrous activity between these studies. Modification of the rubber mat to include deep grooving or raised ridges may increase its coefficient of friction and thus improve slip resistance. Overall, both the duration of standing estrus and number of mounts received during standing estrus were low and the majority of standing estrus events were of low intensity and low duration indicating subestrus was common in these cows.

Floor surface had no significant effect on reproductive performance during the breeding season. In the absence of differences in estrous behaviour and estrus detection rates, it is not surprising that differences in reproductive performance were not detected. Overall reproductive performance was poor, but not untypical of autumn-calving herds.

The results reported here refute the hypothesis that fitting cushioned flooring necessarily improves cow health, welfare and reproduction. Possible differences in responses between primiparous and pluriparous cows were not examined here. The design of the cushioned flooring may have a critical bearing on its effectiveness and the alterations suggested here may improve future rubber flooring. This view is supported by the conclusions of Van Der Tol et al. (2005) who stated that "tractional properties of floors should be the main design criteria in the development of better flooring surfaces for cattle".

\section{Conclusion}

Cows have a preference for standing on softer surfaces when not eating. However, the rubber flooring had only negligible beneficial effects on claw health and no effect on estrous events or reproductive performance.

\section{Acknowledgments}

We thank R.J. Mooney for supplying the rubber flooring (RJM Anti-Lameness Mat ${ }^{\circledR}$ ), Jonathon Kenneally and Tom Condon for their technical assistance and students Hilde Aardema and Susan Arts from the Faculty of Veterinary Medicine in Utrecht for their help. 


\section{References}

Bergsten, C., 2001. Effects of conformation and management system on hoof and leg disease and lameness in dairy cows. Vet. Clinic. North. Am. 17, 1-23.

Bergsten, C., Frank, B., 1996. Sole haemorrhages in tied primiparous cows as an indicator of periparturient laminitis: effects of flooring and season. Acta Vet. Scand. 37, 383-394.

Bergsten, C., Herlin, A.H., 1996. Sole haemorrhages and heel horn erosion in dairy cows: the influence of housing system in their prevalence and severity. Acta Vet. Scand. 37, 395-408.

Bergsten, C., Pettersson, B., 1992. The cleanliness of cows tied in stalls and the health of their hooves as influenced by the use of electronic trainers. Prev. Vet. Med. 13, 229-238.

Bergsten, C., Hancock, D.D., Gay, J.M., Gay, C.C., Fox, L.K., 1998. Claw diseases: the most common cause of dairy lameness diagnoses, frequencies and risk groups in a university herd. Proc. Bovine Pract. 31, 188-197.

Blowey, R.W., 2005. Factors associated with lameness in dairy cattle. In Practice 27, 154-162.

Britt, J.H., Scott, R.G., Armstrong, J.D., Whitacre, M.D., 1986. Determinants of estrous behaviour in lactating Holstein cows. J. Dairy Sci. 69, 2195-2202.

De Silva, A.W.M.V., Anderson, G.W., Gwazdauskas, F.C., McGilliard, M.L., Lineweaver, J.A., 1981. Interrelationships with estrous behaviour and conception in dairy cattle. J. Dairy Sci. 64, 2409-2418.

Fregonesi, J.A., Leaver, J.D., 2001. Behaviour, performance and health indicators of welfare for dairy cows in strawyard or cubicle systems. Livestock Prod. Sci. 68, 205-216.

Fregonesi, J., Tucker, C.B., Weary, D.M., Flower, F.C., Vittie, T., 2004. Effect of rubber flooring in front of the feed bunk on the time budgets of dairy cattle. J. Dairy Sci. 87, 1203-1207.

Greenough, P.R., Vermunt, J.J., 1991. Evaluation of sub-clinical laminitis in a dairy herd and observations on associated nutritional and management factors. Vet. Rec. 128, 11-17.

Irps, H., 1983. Results of research projects into flooring preferences of cattle. In: Baxter, S.H., Baxter, M.R., MacCormack, J.A.C. (Eds.), Farm Animal Housing and Welfare. Seminar in the Commission of the European Communities Programme of Coordination of Research on Animal Welfare. Martinus Nijhoff Publishers, The Hague, pp. 200-215.

Jungbluth, T., Benz, B., Wandel, H., 2003. Soft walking areas in loose housing systems for dairy cows. In: Proceedings of the Dairy Housing Conference, Fort Worth, Texas. Am. Soc. Agric. Eng., St. Joseph, MI, pp. 171-177.

Larkin, J., Sreenen, J.M., Boland, M.P., Diskin, M.G., 2003. Effect of underfoot-surface conditions and group size on expression of oestrus in heifers. In: Proceedings of the Agricultural Research Forum, Tullamore, Ireland, p. 85.

Leach, K.A., Logue, D.N., Kempson, S.A., Offer, J.E., Ternent, H.E., Randall, J.M., 1997. Claw lesions in dairy cattle: development of sole and white line haemorrhages during the first lactation. Vet. J. 154, 215-225.

Leonard, F.C., O'Connell, J., O'Farrell, K., 1994. Effect of different housing conditions on behaviour and foot lesions in Friesian heifers. Vet. Rec. 134, 490-494.

Leonard, F.C., O’Connell, J.M., O’Farrell, K.J., 1996. Effect of overcrowding on claw health in first-calved heifers. Br. Vet. J. 152, 459-472.

Livesey, C.T., Harrington, T., Johnston, A.M., May, S.A., Metcalf, J.A., 1998. The effect of diet and housing on the development of sole haemorrhages, white line haemorrhages and heel erosions in Holstein heifers. Anim. Sci. 67, 9-16.

Lucy, M.C., 2001. Reproductive loss in high-producing dairy cattle: where will it end? J. Dairy Sci. 84, 1277-1293.

Manske, T., Hultgren, J., Bergsten, C., 2002. Topical treatment of digital dermatitis associated with severe heel horn erosion in Holstein heifers. Prev. Vet. Med. 53, 215-231.

Mee, J., 2004. Temporal trends in reproductive performance in Irish dairy herds and associated risk factors. Ir. Vet. J. 57, 158-166.

Offer, J.E., Logue, D.N., Offer, N.W., Marsden, M., 2004. The effect of concentrate composition on lameness and hoof health in dairy cows. Vet. J. 167, 111-113.

Offer, J.E., McNulty, D., Logue, D.N., 2000. Observations of lameness, hoof conformation and development of lesions in dairy cattle over four lactations. Vet. Rec. 147, 105-109.

O’Connell, J.M., Meaney, W.J., Giller, P.S., 1991. An evaluation of four cubicle designs using cattle behaviour criteria. Ir. Vet. J. 44, 8-13.

Peterse, D.J., 1980. Judgement of bovine claws by the occurrence of sole lesions. PhD Thesis. Utrecht, The Netherlands.

Philipot, J.M., Pluvinage, P., Cimarosti, I., Sulpice, P., Bugnard, F., 1994. Risk factors of dairy cow lameness associated with housing conditions. Vet. Res. 25, 244-248.

Rodtian, P., King, G., Subrod, S., Pongpiachan, P., 1996. Oestrous behaviour of Holstein cows during cooler and hotter tropical seasons. Anim. Rep. Sci. 45, 47-58. 
Ryan, M.G., 1998. Strategies for the feeding and management of dairy cows for both seasonal and non-seasonal milk production systems in Ireland. PhD Thesis. N.U.I., pp. 1-334.

Statistical Analysis Systems, 2000. The SAS system for Windows Version 8. SAS Institute Inc., Cary, NC 27513, USA.

Stefanowska, J., Swierstra, C., Braam, C.R., Hendriks, M.M.W.B., 2001. Cow behaviour on a new grooved floor in comparison with slatted floor, taking claw health and floor properties into account. Appl. Anim. Behav. Sci. 71, 87103.

Telezhenko, E., Bergsten, C., 2005. Influence of floor type on the locomotion of dairy cows. Appl. Anim. Sci. 93, 183197.

Telezhenko, E., Lidfors, L., Bergsten, C., 2004. Preferences of dairy cows for walking and standing on different floors. In: Proceedings of the 38th International Congress of the International Society for Applied Ethology, Helsinki, 3rd-7th August, p. 120.

Tucker, C.B., Weary, D.M., de Passille, A.M., Campbell, B., Rushen, J., 2006. Flooring in front of the feed bunk affects feeding behaviour and use of freestalls by dairy cows. J. Dairy Sci. 89, 2065-2071.

Vailes, L.D., Britt, J.H., 1990. Influence of footing surface on mounting and other sexual behaviors of estrual Holstein cows. J. Anim. Sci. 68, 2333-2339.

Van Der Tol, P.P.J., Metz, J.H.M., Noordhuizen-Stassen, E.N., Back, W., Braam, C.R., Weijs, W.A., 2005. Frictional forces required for unrestricted locomotion in dairy cows. J. Dairy Sci. 88, 615-624.

Vermunt, J.J., Greenough, P.R., 1994. Predisposing factors of laminitis in cattle. Br. Vet. J. 150, 151-164.

Vokey, F.J., Guard, C.L., Erb, H.N., Galton, D.M., 2001. Effects of alley and stall surfaces on indices of claw and leg health in dairy cattle in a free-stall barn. J. Dairy Sci. 84, 2686-2699.

Webster, A.J.F., 2002. Effect of housing practices on the development of foot lesions in dairy heifers in early lactation. Vet. Rec. 151, 9-12.

Webster, A.J.F., 2001. Effects of housing and two forage diets on the development of claw horn lesions in dairy cows at first calving and in first lactation. Vet. J. 162, 56-65. 